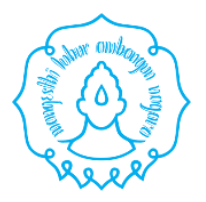

Jurnal Kumara Cendekia

https://jurnal.uns.ac.id/kumara

\title{
PENGARUH PERCEPTUAL MOTOR TRAINING (PMT) TERHADAP PERKEMBANGAN MOTORIK KASAR PADA ANAK USIA 5-6 TAHUN
}

\author{
Lusi Lukmawati ${ }^{1}$,Muh. Ismail Sriyanto ${ }^{2}$,Muh. Munif Syamsuddin ${ }^{1}$ \\ ${ }^{1}$ Program Studi PG-PAUD, Universitas Sebelas Maret \\ ${ }^{2}$ Program Studi PGSD, Universitas Sebelas Maret
}

Email :lusilukmawati22@gmail.com, ismail48@staff.uns.ac.id,wandamunif@yahoo.com

\begin{abstract}
ABSTRAK
Penelitian ini bertujuan untuk mengetahui pengaruh Perceptual Motor Training (PMT) terhadap perkembangan motorik kasar pada anak usia 5-6 tahun. Penelitian ini merupakan penelitian kuantitatif dengan jenis penelitian murni (True Experimental Design) dengan rancangan Before-After Design. Pengambilan sampel menggunakan teknik Random Assigment. Responden penelitian ini adalah 21 anak usia 5-6 tahun di TK Al Islam 4 Surakarta sebagai kelompok eksperimen dan 21 anak usia 5-6 tahun di TK Al Huda Surakarta sebagai kelompok kontrol. Uji validitas data menggunakan koefisien korelasi dan analisis data menggunakan statistik parametrik setelah data dinyatakan normal dan homogen dengan taraf signifikasi > 0,05. Uji normalitas dan uji homogenitas menggunakan Kolmogorov Smirnov dan Levene test for Equality of Variance.Uji hipotesis menggunakan t-test dengan SPSS 22 for windows.Simpulan hasil penelitian ini menunjukkan Perceptual Motor Training (PMT) memberikan pengaruh positif terhadap perkembangan motorik kasar pada anak usia 5-6 tahun yang dibuktikan oleh adanya perbedaan yang signifikan antara kelompok eksperimen dan kelompok kontrol $(\rho>0,05)$. Hasil analisis data menunjukkan bahwa nilai postest unjuk kerja keterampilan motorik kasar pada kelompok eksperimen dan kelompok kontrol menunjukkan 38,24 dan 34,52. Kesimpulan penelitian ini menunjukkan bahwa terdapat pengaruh Perceptual Motor Training (PMT) terhadap perkembangan motorik kasar anak usia 5-6 tahun.Peningkatan motorik kasar anak dapat dilihat dari anak yang mampu untuk melakukan berbagai macam gerak lokomotor, gerak manipulatif, dan keseimbangan dengan benar dan terarah.
\end{abstract}

Kata Kunci : Perceptual Motor Training (PMT), motorik kasar, prasekolah

\section{ABSTRACT}

This study aimed to determine the effect of Perceptual Motor Training (PMT) on the gross motor development of children aged 5-6 years. This research was quantitatif research used True Experimental Design with Before-After Design. Sampling using Random Assignment. Subject in this study were 21 childrens aged 5-6 years Al Islam 4 Surakarta Kindergarten as a experiment group and 21 childrens age 5-6 years Al Huda Surakarta Kindergarten as a control group. Test the validity using construct correlation coefficient and data analysis in this study used parametric after data stated normal and 
homogeneus with significance level > 0,05. The normality and homogenity using Kolmogorov Smirnov and and Levene of Variance. The hypothesis test used t-test with SPSS 22 for windows. The result of this study showed Perceptual Motor Training (PMT) gives positive influence to the gross motor development of children aged 5-6 years was evidence by the existence of significant difference between experimental group and control group $(\rho>0,05)$. The result on the data analysis showed posttest score gross motor skill on experimental and control group showed 38,24 and 34,52. The conclusion of this research showed that there are effect Perceptual Motor Training (PMT) to the gross motor development of children aged 5-6 years. Increase motor roughage of children can be seen from children who are able to perform various kinds of locomotor motion, manipulative motion, and balance corectly and directionally.

Keywords : Perceptual Motor Training (PMT), gross motor, preschool 


\section{PENDAHULUAN}

Masausia dini merupakan kesempatan ideal bagi anak-anak untuk belajar mengembangkan kontrol atas otot dan gerakan anak. Pada masa ini merupakan masa keemasan atau golden age yang merupakan masa yang tepat untuk dapat mengembangkan berbagai macam potensi serta kemampuan fisik anak.Salah satu faktor penting dalam perkembangan anak adalah kemampuan perseptual motorik.

Penelitian yang telah dilakukan oleh berbagai ahli menyebutkan bahwa perseptual motor dapat meningkatkan siswa dalam tiga bidang pengembangan yaitu kognitif, afektif, dan psikomotor (Sajedi dan Barati, 2014). Kemampuan persepsi motorik harus dikembangkan diawal kehidupan anak secara alami, bahkan dalam setiap gerakan manusia.Akan tetapi, perkembangan motorik manusia tergantung pada lingkungan, situasi, dan posisinya. Dalam urutan untuk mengembangkan perseptual motorik, awal pengalaman dari gerakan anak- anak penting terhadap perkembangan motorik kasar pada anak usia dini.

Anak-anak mendekati tahap perseptual melalui menyentuh, meraih,

mengambil, melepaskan, menyeimbangkan, merangkak, dan berjalan.

Perkembangan zaman yang semakin pesat, anak lebih banyak menghabiskan waktu bermainnya dengan gadget daripada bermain dengan temen-temannya. Hal ini sesuai dengan penelitian Lee, dkk., (2015) yang menyatakan bahwa aktivitas fisik anak-anak yang tinggal di pedesaan lebih banyak daripada aktivitas fisik anak-anak yang tinggal di perkotaan. Anak-anak perkotaan lebih sering memanfaatkan waktu luang dengan menonton televisi maupun bermain gadget daripada bermain diluar rumah dengan tementemannya.Hal tersebut menyebabkan perkembangan motorik anak tidak berkembang secara maksimal.

Berdasarkan hasil observasi pada tanggal 5-9 Maret 2018 di TK Al Islam 4 Surakarta peneliti menemukan bahwa banyak terdapat permasalahan dalam pembelajaran. Permasalahan tersebut antara lain dalam pengembangan keterampilan motorik. Pengembangan keterampilan motorik lebih dominan dalam pengembangan keterampilan motorik halus. 
KUMARA CENDEKIA Vol. 7 No. 2 Juni 2019

Apabila kekurangan dalam pengembangan motorik tidak segera diperbaiki, maka akan memiliki dampak besar pada anak-anak dalam berbagai aspek kehidupannya kelak. Keterampilan motorik merupakan fondasi untuk pengembangan bidang lain. Anak-anak yang sudah mampu mengontrol motoriknya, mereka akan belajar menjadi individu yang mandiri, mengeksplorasi lingkungan, berinteraksi dengan teman sebaya, dan mengembangkan keterampilan sosial lainnya (Sun, dkk., 2010)

\section{Mengembangkan}

keterampilan motorik kasar pada anak usia dini dapat dilakukan melalui kegiatan yang menyenangkan. Pengembangan keterampilan motorik kasar pada anak usia dini dapat dilakukan melalui kegiatan yang menarik dan menyenangkan. Kegiatan ini dapat dilakukan melalui serangkaian permainan (Jones, dkk., 2016) Kemampuan motorik kasar pada anak usia dini bukanlah kemampuan yang tumbuh secara alami. Tetapi, perlu adanya stimulasi untuk mengembangkan kemampuan motorik kasar anak. Berdasarkan studi

Perceptual Motor Training(PMT) dapat mengembangkan keterampilan motorik pada anak usia dini, baik motorik kasar maupun motorik halus (Sajedi dan Barati, 2014). Sehingga, metode ini disarankan untuk mengembangkan keterampilan motorik di berbagai pusat prasekolah di Indonesia. PMT bermanfaat bagi perkembangan motorik kasar anak (Tabar, 2014) Hasil tersebut diperkuat oleh ahli lain yang menyatakan bahwa PMTdapat meningkatkan kesehatan dan semua aspek perkembangan pada anak (Johnstone dan Ramon, 2011).

Berdasarkan uraian di atas, maka peneliti tertarik untuk mengkaji dan memodifikasi tentang pengaruh penerapan $\quad P M T$ terhadap perkembangan motorik kasar pada anak usia 5-6 tahun, yang dirumuskan dengan judul penelitian sebagai berikut, "Pengaruh Perceptual Motor Training $\quad(P M T) \quad$ terhadap Perkembangan Motorik Kasar pada Anak Usia 5-6 tahun”.

\section{Motorik Kasar}

Kemampuan motorik kasar merupakan kemampuan menggunakan otot besar dengan melibatkan tangan, kaki, dan seluruh tubuh yang menjadi 
dasar bagi pengembangan keterampilan motorik yang lebih kompleks dan menuntut kekuatan fisik dan keseimbangan. Motorik kasar memiliki beberapa aspek diantaranya adalah aspek perkembangan motorik kasar terdiri dari gerak lokomotor, gerak stasioner/ non lokomotor, dan gerak manipulatif (Rahyubi, 2012; Santrock, 2007; Liu, dkk. , 2014). Aspek kemampuan motorik kasar anak terdiri dari 1) gerak lokomotor,yaitu gerak untuk berpindah, 2) gerak stasioner, yaitu gerak untuk mempertahankan keseimbangan, dan 3)gerak manipulatif, yaitu gerak untuk memanipulasi benda- benda (Zawi, Choon Lian, dan Abdullah ,2014). Keterampilan motorik yang lebih kompleks disebut sebagai gerakan keterampilan fundamental, dan selanjutnya dikategorikan dalam dua aspek yaitu 1) keterampilan lokomotor, yaitu keterampilan yang melibatkan gerakan tubuh seperti berlari dan melompat, 2) keterampilan kontrol obyek, yaitu aktivitas yang dimanipulasi besar-besaran oleh obyek. Misalnya : melempar, menangkap, dan menendang (Kokstejn, dkk.,2017)
Perceptual Motor Training (PMT)

\section{Perceptual Motor Training}

(PMT) merupakan merupakan suatu pelatihan motorik yang melatih olah gerak dan kognitif secara bersama-sama yang terdiri dari kegiatan motorik misalnya latihan keseimbangan statis (berdiri dengan satu kaki) sambil membaca alfabet , latihan keseimbangan anak saat berjalan (keseimbangan dinamis) sambil menghitung, koordinasi bilateral misalnya berlari sambil menyusun balok, tes kekuatan, koordinasi mata dan lengan, persepsi auditori dan visual.

Aspek-aspek yang terkandung dalam Perceptual Motor Training (PMT) meliputi kesadaran tubuh, keseimbangan, lateralitas, kemampuan manipulatif, kemampuan lokomotor, pemahaman, pengenalan bentuk, dan persepsi.Penerapan Perceptual Motor Training (PMT)terhadap perkembangan motorik kasar pada anak usia 5-6 tahun dilakukan dengan 6 kali pertemuan dengan penerapan aspek-aspek yang 
terdapat dalam metode tersebut. Aspek- aspek tersebut meliputi gerak lokomotor, gerak manipulatif, gerak keseimbangan, lateralitas, pengenalan bentuk, dan persepsi.Pelaksanaan $\quad P M T$ meliputi beberapa kegiatan motorik kasar yang telah dimodifikasi oleh peneliti dan saling berkaitan. Tujuannya agar lebih mudah diterapkan dalam pembelajaran anak usia dini. Latihan dalam PMTdilakukan melalui berbagai latihan diantaranya locomotor training, bilateral activity, unilateral activity, cross lateral activity, manipulative training, dan combination activities (Johnstone dan Ramon, 2011)

\section{METODE PENELITIAN}

$$
\begin{aligned}
& \text { Jenis penelitian } \begin{array}{r}
\text { yang } \\
\text { adalah }
\end{array} \\
& \text { penelitian } \\
& \text { eksperimen murni (true eksperiment } \\
& \text { design).Tujuan dari penelitian ini } \\
& \text { adalah untuk mengetahui pengaruh } \\
& \text { pemberian Perceptual Motor Training } \\
& \text { (PMT) terhadap perkembangan } \\
& \text { motorik kasar pada anak usia 5-6 } \\
& \text { tahun. Penelitian ini akan } \\
& \text { dilaksanakan di TK Al Islam IV }
\end{aligned}
$$

Surakarta yang beralamatkan di Jl. KH. Agus Salim 7, Sondakan, Laweyan, Surakarta pada kelompok B semester 1 tahun ajaran 2018/2019, sebagai kelompok eksperimen. Sedangkan untuk kelompok kontrol dalam penelitian ini dilaksanakan di kelompok B TK Al Huda Surakarta yang beralamatkan di J1. Siwalan No. 35, Jajar, Laweyan, Surakarta.Pada kelompok B semester 1 tahun ajaran 2018/2019.

Alasan pemilihan TK Al Islam 4 Surakarta dan TK Al Huda Surakarta sebagai tempat penelitian karena kedua

TK tersebut memiliki sampel yang cukup banyak serta banyak anak yang belum memenuhi kriteria dalam perkembangan motorik kasar pada anak usia 5-6 tahun.

$$
\text { Penelitian ini dilaksanakan }
$$
selama delapan bulan yaitu pada bulan Maret 2018 sampai dengan bulan Oktober 2018. Waktu penelitian ini dimulai dari pengajuan judul, penyusunan proposal, seminar proposal, pengurusan perizinan, pengumpulan dan analisis data, penyusunan laporan hingga ujian skripsi serta revisi laporan skripsi. 
Teknik pengambilan sampel yang digunakan dalam penelitian ini adalah random assignmen, yaitu teknik pengambilan sampel secara acak. Pengumpulan data dilaksanakan dengan menggunakan tes unjuk kerja perkembangan motorik kasar anak usia dini. Metode pengumpulan data menggunakan teknik rating scale dengan skala $1-4$.

Teknik uji validitas instrumen menggunakan koefisien korelasi, sedangkan teknik uji reliabilitas dalam penelitian ini menggunakan uji Alpha Cronbach's. Teknik analisis data dalam penelitian ini menggunakan uji normalitas dengan rumus Kolmogorov Smirnov dan uji homogenitas dengan rumus Levene test for Equality of Varianceyaitu data homogen apabila $\rho>0,05$.

Pengumpulan data dilakukan melalui tes unjuk kerja dan dokumentasi.Pengujian hipotesis menggunakan statistik parametrik yaitu data dinyatakan normal dan homogen. Kemudian untuk mengetahui adakah perbedaan dua perlakuan dalam penggunaan Perceptual Motor Training(PMT)terhadap perkembangan motorik kasar anak usia dini dengan uji-t yaitu dengan menggunakan independent sample $t$ testkarena ada dua kelompok yang dibandingkan yaitu kelompok kontrol dan kelompok eksperimen. Dasar pengambilan keputusan adalah adanya perbedaan yang signifikan, yaitu apabila signifikansi < 0,05. Data yang sudah terkumpul kemudian diuji dengan menggunakan bantuan SPSS 22 for windows.

\section{HASIL DAN PEMBAHASAN}

Hasil analisis data setiap variabel pada penelitian ini menggunakan statistik deskriptif. Berikut ini hasil dari pretest dan posttestpenelitian yang berisikan nilai minimum, nilai maksimun, rata-rata (mean), simpangan baku (standar

deviasi). Hasil deskripsi data dijelaskan pada tabel 1 dibawah ini.

Tabel 1. Hasil Deskripsi Data

Kelompok $N$ Range Min Max Mean Std. Dev Median

\begin{tabular}{|c|c|c|c|c|c|c|c|}
\hline \multirow{2}{*}{ Nilai Pretes } & Kontrol & 21 & 9 & 2837 & 33,3 & 2,54 & 34 \\
\hline & Eksperimen & 21 & 9 & 2938 & 33,4 & 2,63 & 34 \\
\hline & Kontrol & 21 & 9 & 3039 & 34,5 & 1,97 & 35 \\
\hline
\end{tabular}




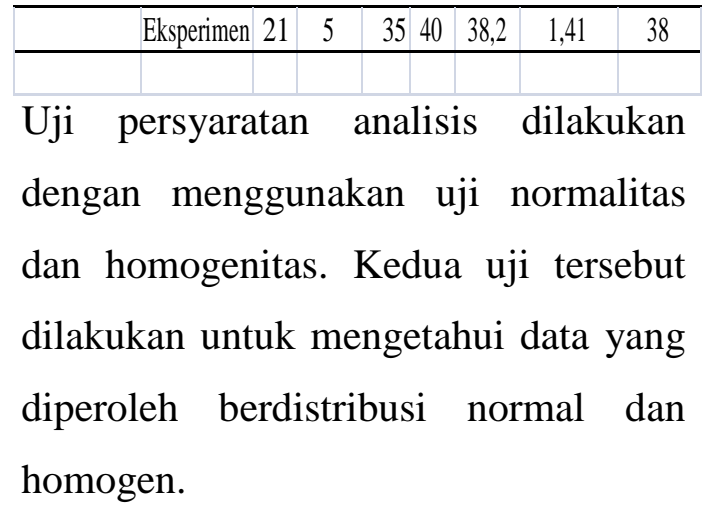

Uji hipotesis dilakukan dengan menggunakan independent sample $t$ test.Hasil uji hipotesis dapat dilihat pada Tabel 2 dibawah ini :

Tabel 2. Hasil Uji Independent Sample t- test

\begin{tabular}{|c|c|c|c|c}
\hline & & N & Mean & P \\
\hline Sebelum & Eksperimen & 21 & 33,43 & \\
\cline { 1 - 3 } Perlakuan & Kontrol & 21 & 33,33 & \multirow{2}{*}{0,906} \\
\hline Setelah & Eksperimen & 21 & 38,24 & \\
\cline { 1 - 3 } Perlakuan & Kontrol & 21 & 34,52 & 0.000 \\
\hline
\end{tabular}

Berdasarkan hasil uji hipotesis dapat diketahui bahwa terdapat pengaruh pemberian Perceptual Motor Training (PMT) terhadap perkembangan motorik kasar pada anak usia 5-6 tahun. Rata-rata pretest 33,4 meningkat menjadi 38,2 setelah dilakukan posttest.Berdasarkan STPPA (Standar Tingkat Pencapaian Perkembangan Anak) yang tertera dalam Permendikbud nomor 137 tahun
2014, salah satu aspek perkembangan pada anak usia dini merupakan perkembangan motorik kasar. Beberapa hal yang melandasi bahwa Perceptual Motor Training(PMT) memiliki pengaruh terhadap perkembangan motorik kasar pada anak usia 5-6 tahun adalah sebagai berikut :

Pertama PMT merupakan suatu metode yang digunakan untuk mengembangkan kemampuan motorik kasar pada anak. Metode ini merupakan kegiatan yang digunakan untuk mengembangkan kemampuan motorik kasar dan kognitif secara bersama (Johnstone dan Ramon, 2011), sehingga secara tidak langsung kemampuan motorik dan konsentrasi anak akan terlatih menjadi lebih baik. Kegiatan yang dilakukan dalam metode ini berdasarkan teori yang telah dijelaskan dalam metode tersebut, tetapi disesuaikan dan dimodifikasi sendiri oleh peneliti disesuaikan dengan kondisi sekolah dan kemampuan responden dalam penelitian. Kedua, dalam pelaksanaan penelitian menggunakan PMTdilakukan dengan pertandingan (kompetisi). Anak dibagi menjadi dua regu yang masing-masing regu 
memiliki jumlah peserta yang sama. Kegiatan dilakukan dengan perlombaan, tujuannya agar anak lebih aktif dalam kegiatan dan termotivasi untuk mengikuti kegiatan pembelajaran. Semua anak diberikan kesempatan yang sama dalam mengikuti kegiatan, sehingga tiak ada kesenjangan antara anak satu dengan yang lain. Ketiga, manfaat lain yang dapat diperoleh anak setelah mengikuti latihan PMTadalah dapat meningkatkan kepercayaan dirinya (Karghand dan Pour, 2016) Hal ini dapat dilihat pada saat anak mampu melaksanakan suatu tugas dalam treatment dalam PMTanak akan merasa puas dan bangga sehingga ada beberapa anak yang berkata kepada temannya "Hore, aku sudah bisa." penggunaan media pembelajaran yang menarik dapat memberikan sumbangan positif dalam pelaksaan kegiatan. Anak lebih tertarik dan memiliki antusias yang tinggi selama pelaksaan kegiatan. Beberapa media tersebut diantaranya matras yang dibuat sendiri oleh peneliti yang membuat anak tertarik kegiatan dan media pembelajaran. Keuntungan yang diperoleh adalah anak lebih mudah untuk latihan gerakan secara tepat. Kelima, keterampilan motorik kasar pada anak usia dini dapat mempengaruhi aspek perkembangan yang lain, misalnya kemampuan sosial dan perhatian (atensi). Hal ini dapat dibuktikan pada saat temannya bertanding, teman yang tidak mengikuti perlombaan memberikan semangat agar teman yang bertanding berhasil memenangkan pertandingan. Sehingga, dapat mengembangkan kemampuan sosial pada anak usia prasekolah. Selain itu, anak yang sedang melakukan pertandingan dapat melatih perhatiannya. Hal ini dibuktikan, pada saat anak bertanding memerlukan konsentrasi yang baik agar dapat melaksanakan tugas kognitifnya setelah mempraktekkan kegiatan motorik.

Selain memiliki beberapa manfaat yang telah diuraikan diatas, penelitian ini juga memiliki beberapa hambatan. Beberapa hambatan yang dialami peneliti diantaranya adalah anak mengeluh kelelahan selama pelaksanaan penelitian. Sehingga, peneliti harus mempunyai strategi Keempat, khusus agar mampu menarik minat anak untuk mengikuti kegiatan pembelajaran. 
Penelitian ini diharapkan dapat menjadi referensi dalam kegiatan pembelajaran motorik kasar yang menarik dan menyenangkan dalam pendidikan anak usia dini. Sehingga, perkembangan motorik kasar anak usia dini dapat lebih distimulasi dan berkembang menjadi lebih baik.

\section{KESIMPULAN}

Penelitian ini mengkaji tentang penerapan Perceptual Motor Training (PMT) yang merupakan metode pembelajaran yang melibatkan peserta didik dalam pengembangan motorik kasar melalui kegiatan permainan yang menarik dan menyenangkan.Model

pembelajaran PMT merupakan suatu metode yang digunakan untuk mengembangkan aspek fisik motorik dan kognitif secara bersama- sama.Model pembelajaran ini mendorong anak untuk mengembangkan motorik kasar secara benar dan terarah sambil mengembangkan kognitifnya. Kegiatan ini dilakukan secara kompetisi agar anak lebih tertarik dan antusias dalam mengikuti kegiatan. Hasil penelitian menunjukkan bahwa terdapat pengaruh positif penerapan $P M T$ terhadap perkembangan motorik kasar pada anak usia 5-6 tahun.Ratarata nilai posttest pada kelompok eksperimen mengalami peningkatan secara signifikan. Anak-anak sudah mampu melakukan berbagai gerak lokomotor, keseimbangan, dan manipulatif dengan benar dan terarah. Sehingga, dapat disimpulkan bahwa PMT dapat berpengaruh terhadap perkembangan motorik kasar pada anak usia 5-6 tahun.

\section{DAFTAR PUSTAKA}

Jones, R A., dkk. (2016). Journal of science and medicine in sport promoting gross motor skill and phisical activity in childcare : a translational randomized controlled trial. Journal of Science and Medicine in Sport.19(9), 744-749.Diperoleh pada 1 Juni 2018, dari https://www.jsams.org

Johnstone, J. A., \& Ramon, M. (2011). Perceptual-motor activities for children : an evidence-based guide to building physical and 
cognitive skills. USA: Versa Internati Press. Diperoleh pada 8 April 2018,

http://www.humankinetics.com/ products/all products/perceptual-motoractivities-for-children

Karghand, Z. A., \& Pour, M. E. (2016). The effect of perceptual-motor activities training on gross motor skills of autistic children. onal Journal of Environmental Research and Public Health, 146161. Diperoleh pada 18

Maret 2018, dari https://www.ncbi.nlm.nih.g ov

International Society of communication

and Development amperatratitiedisorder and

, 101-106. ISSN 0362-2428

Diperoleh pada 6 Maret 2018, dari http://www.europeansp.or $\mathrm{g}$ typically developing children on TGMD-2. Journal of Child \& Adolescent Behavior, II (1), 123-126.

Kokstejn, J., Musalek, M., Stastny, P., \& Golas, A. (2017). Fundamental motor skills of czech children at the end of the preschool period. Acta Gymnica, 47 (4), 193-200. Diperoleh pada 6 April 2018, dari https://www.researchgate. net

Diperoleh pada 18 Maret 2018, dari https://www.omicsonline.org

Papalia, D. E., Feldman, R. D., \& Olds,

S. W. (2013). Human development edisi 10 Buku 1. Jakarta: Salemba Humanika.

Lee, S. T., Wong, J. E., Shanita, S. N., Ismail, M. N., Deurenberg, P., \& Poh, B. K. (2015). Daily physical activity and screen time, but not other sedentary activities, are associated with measures of obesity during childhood.

Rahyubi, H. (2012). Teori-teori belajar dan aplikasi pembelajaran motorik. Bandung: Nusa Media.

Sajedi, F., \& Barati, H. (2014). The effect of perceptual motor training on motor skills of 
preschool children. Iranian

Rehabilitation Journal, 12, 14-

17. Diperoleh pada 6 Maret 2018, dari http://irj.uswr.ac.ir

Santrock, J. W. (2007). Perkembangan anak. Jakarta: Penerbit Erlangga.

Sun, S. H., Zhu, Y. C., Shih, C. L., Lin, C. H., \& Wu, S. K. (2010). Development and initial validation of the preschooler gross quality scale. Developmental Disabilities, 31,

1187-1196. Diperoleh pada 5 Maret 2018, dari Development and initial validation of the Preschooler Gross Motor Quality Scale - ScienceDirect

Tabar, S. M. B. (2014). Effect of eight weeks of perceptual motor training on perceptual motor performance in children age 810 years in Kermanshah, International Journal of Sport Studies , 4 (4), 421-427 Diperoleh pada 24 Maret 2018, dari http://www.ijssjournal.com
20 Maret 2018,

dari 
KUMARA CENDEKIA Vol. 7 No. 2 Juni 2019 